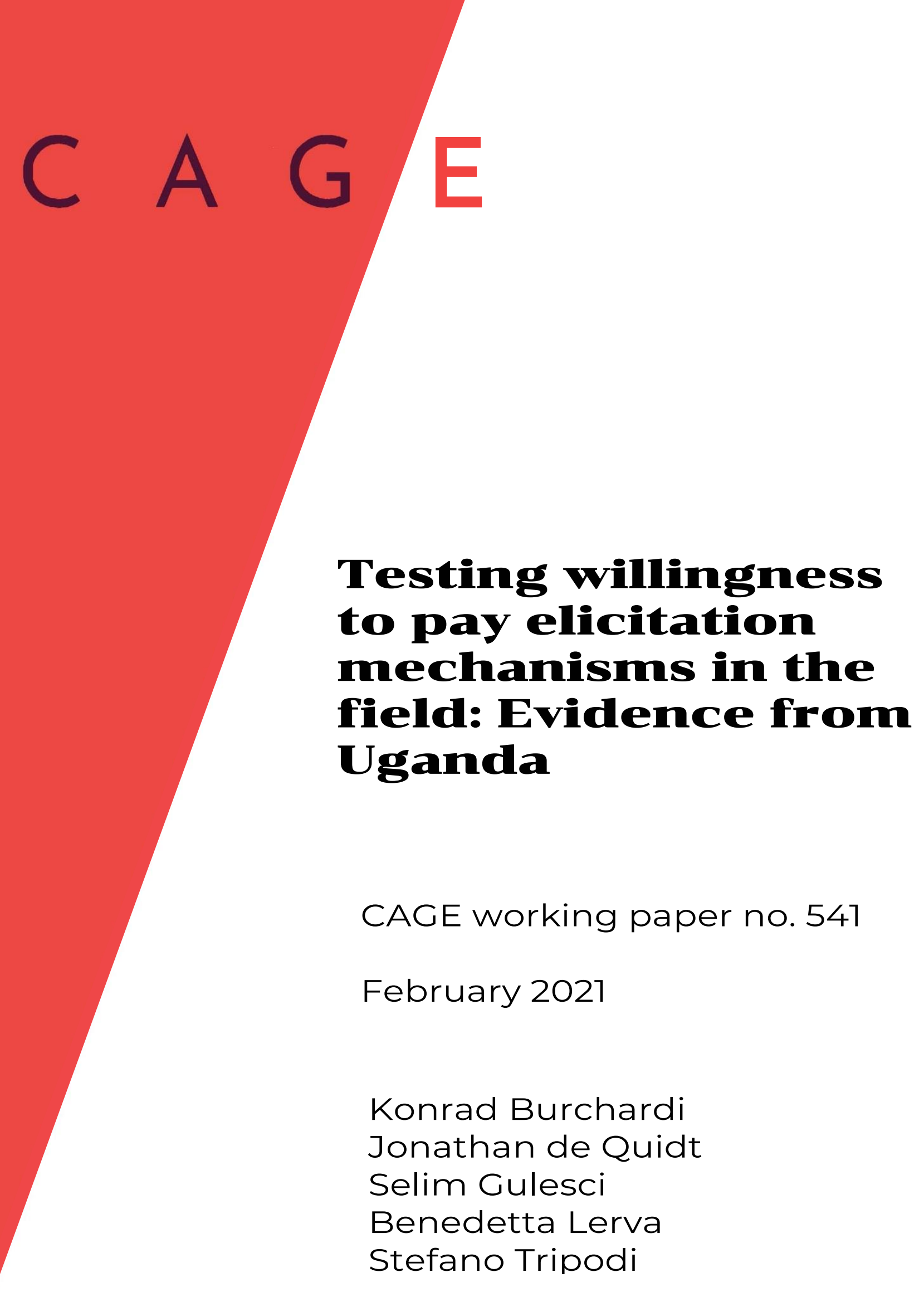




\title{
Testing Willingness to Pay Elicitation Mechanisms in the Field: Evidence from Uganda*
}

\author{
Konrad Burchardi ${ }^{\dagger} \quad$ Jonathan de Quidt ${ }^{\ddagger} \quad$ Selim Gulesci ${ }^{\S}$ \\ Benedetta Lerva Stefano Tripodil
}

February 11, 2021

\begin{abstract}
Researchers frequently use variants of the Becker-DeGroot-Marschak (BDM) mechanism to elicit willingness to pay (WTP). These variants involve numerous incentive-irrelevant design choices, some of which carry advantages for implementation but may deteriorate participant comprehension or trust in the mechanism, which are well-known problems with the BDM. We highlight three such features and test them in the field in rural Uganda, a relevant population for many recent applications. Comprehension is very high, and 86 percent of participants bid optimally for an induced-value voucher, with little variation across treatments. This gives confidence for similar applications, and suggests the comprehension-expediency trade-off is mild.

JEL codes: C90, C93, D44, O12
\end{abstract}

${ }^{*}$ We thank Apollo Tumusiime and Charles Angebault for outstanding field support. This research was supported by the Swedish Research Council, grant no. 2015-03426. Burchardi, de Quidt, and Lerva acknowledge financial support from Handelsbanken's Research Foundations. All errors and omissions are our own.

${ }^{\dagger}$ Institute for International Economic Studies, Stockholm University, BREAD, CEPR, CESifo, ThReD. E-mail: konrad.burchardi@iies.su.se

¥Institute for International Economic Studies, Stockholm University, CAGE, CEPR, CESifo, ThReD. E-mail: jonathan.dequidt@iies.su.se

§ Trinity College, Dublin, BREAD, CEPR, EUDN, J-PAL, LEAP. E-mail: gulescis@tcd.ie.

TMistra Center for Sustainable Markets, Stockholm. E-mail: benedetta.lerva@gmail.com.

"Department of Economics, Copenhagen Business School. E-mail: st.eco@cbs.dk. 


\section{Introduction}

Measurement of willingness to pay (WTP) is an important part of the economist's toolkit. Conceptually, knowledge of consumers', households', or firms' WTP for goods or services is key to constructing non-parametric demand curves, which can be used to predict the effects of counterfactual policies such as price subsidies. Furthermore, standard elicitation mechanisms allow the researcher to conduct selective trials (Chassang et al., 2012), which measure marginal treatment effects as a function of WTP. Marginal treatment effects can be used to compute a variety of policy-relevant treatment effects (Heckman and Vytlacil, 2005).

In recent years development economists have increasingly adopted these techniques in the field. Researchers have studied demand for health products (Hoffmann, 2009; Hoffmann et al., 2009; Cohen and Dupas, 2010; Ashraf et al., 2010; Dupas, 2014; Fischer et al., 2016; Hoffmann, 2018; Grimm and Hartwig, 2018; Fischer et al., 2019; Berry et al., 2020), improved latrines (Yishay et al., 2017), fuel-efficient stoves (Berkouwer and Dean, 2020), solar electricity (Grimm et al., 2020), education programs (Berry and Mukherjee, 2019; Burchardi et al., 2020a), business training (Maffioli et al., 2020), rainfall insurance and agricultural information (Cole et al., 2020), farmer training (Lerva, 2020), and fertilizer (Burchardi et al., 2020b).

The dominant approach to WTP elicitation uses some variant of the classic Becker, DeGroot, and Marschak (1964) (BDM) mechanism. These variants share a common structure. First, participants report a WTP value, $W$. Second, a random price $P$ is drawn. Third, if $W T P \geq P$, the participant purchases the good at price $P$, otherwise they do not purchase and pay nothing. This mechanism shares the incentive properties of a second-price sealed-bid auction: truthful reporting is a weakly dominant strategy.

That approach is persuasive and powerful in theory. This paper is concerned with its practical implementation. There are many incentive-equivalent ways to implement this structure, with different auxiliary properties. Some have statistical or practical advantages for the experimenter; they elicit richer data or give the experimenter more control over the randomization. But these may come at the cost of participant comprehension or trust in the mechanism. This is important, because it is widely recognized that even highly educated participants can find second-price sealed-bid auctions difficult to understand (Kagel et al., 1987; Ausubel, 2004; Li, 2017), so equivalent incentives may not lead to equivalent behavior. These concerns may be particularly important for field research in low-income countries, where participants have limited education, are unfamiliar with intricate incentive structures and randomization, and may feel unable to verify or trust that the scheme will be honestly implemented (Akbarpour and Li, 2020).

We conduct an experiment in rural Uganda to compare the performance of four 
different implementations of the basic structure described above. These allow us to test the influence of three design features: the response mode (how participants state their WTP); whether prices are randomly assigned onsite after elicitation, or preassigned; and how much information we give participants about the price distribution. As we explain in the next section, these features capture key trade-offs between design expediency and ease of comprehension.

We measure performance in two ways. First, we implement an extensive set of comprehension checks, inspired by those used by Berry et al. (2020). Second, we measure optimal bidding performance, inspired by Cason and Plott (2014). We elicit WTP for an induced-value voucher that is immediately redeemable for its face value in cash: 1,400 Ugandan Shillings (UGX, \$1.27 at 2016 PPP, or around 30 percent of the daily agricultural wage in the region). It is a weakly dominant strategy to report WTP equal to the face value, so deviations from optimal behavior are easy to observe. As an auxiliary check we also examine bidding for a well-known soap product, a more natural transaction but for which optimal behavior is more difficult to define.

We find two main results. First, mechanism comprehension is very high. Participants answer our comprehension checks correctly 90 percent of the time, and approximately 86 percent of participants bid optimally for the voucher. This is reassuring news for other work using similar mechanisms to ours. Second, performance is very similar (and statistically indistinguishable) across our four treatment arms. This suggests that researchers can feel confident in following the approach that best suits their field setting, and readers can be confident in interpreting findings from implementations similar to those we test.

Besides the field applications cited above, we relate to a large experimental literature testing different auction and WTP elicitation mechanisms in lab settings (some relevant examples are Bohm et al. (1997); Rutström (1998); Brebner and Sonnemans (2018)). Most relevant for our design is Cason and Plott (2014), who find that many participants report WTP less than $\$ 2$ for a token worth $\$ 2$. In a field setting, Berry et al. (2020) find that elicited WTP is higher under "take it or leave it" offers than BDM while Cole et al. (2020) find they are more similar. We also relate to the parallel literature on "contingent valuation," which uses hypothetical questions to elicit values of public goods, see e.g. Hanemann (1994).

\section{Design}

We begin this section by motivating our three design features of interest. Then, we describe the four treatments that we use to test them. Finally, we highlight the design features common to all of our treatments. 


\subsection{Design features of interest}

\section{Response mode}

Our first feature of interest is the response mode. The classic approach to the BDM has participants simply state a WTP value on a continuous scale (for a recent implementation see Berry et al. (2020)). A practical advantage of this approach is the richness of the data generated. But it relies on participants being readily able to retrieve or construct their own WTP value, and provides little guidance or prompting to help them evaluate if that is indeed their true (maximum) WTP. ${ }^{1}$

An alternative is to use a Multiple Price List (MPL), sometimes also referred to as a choice list. This approach asks, one-by-one for each of a discrete set of prices, whether the participant would be willing to pay that price should it be drawn. Thus the procedure is broken down into a sequence of isolated "yes/no" questions. This loses the point identification of the classic BDM, giving only interval identification. ${ }^{2}$ But it is arguably more transparent and easier to understand (Andersen et al., 2006).

When implementing MPL, we adopt a format that mimics an ascending auction. Starting at zero, we ask the participant if they are willing to pay each possible price in ascending order, stopping once they say "no." We do this because the ascending auction is obviously strategy-proof (Li, 2017), and by mimicking its format we may improve comprehension. ${ }^{3}$

To summarize, BDM has the statistical advantage of richer data, permitting point identification of WTP, but comprehension may be improved under MPL.

\section{Price revelation}

Our second feature of interest is the price revelation mechanism. A standard approach is to draw the price using a transparent randomizer once WTP has been stated, using a bingo cage, slips of paper in a hat, or some other method. Sometimes (including in our application) the participant draws the random price themselves. We refer to this as Onsite randomization. A key argument for doing so is trust: participants can see the process and verify that it is fair.

This approach has a statistical disadvantage in the context of running a selective trial (Chassang et al., 2012). A selective trial exploits the price randomization in the

\footnotetext{
${ }^{1}$ Berry et al. (2020) augment the approach with a sequence of probing post-elicitation questions that encourage to the participant to consider this. We follow a very similar approach.

${ }^{2}$ If a participant says "yes" to price $P_{t}$ and "no" to price $P_{t+1}$ we learn that her WTP is in the interval $\left[P_{t}, P_{t+1}\right)$.

${ }^{3}$ Note that MPL is not obviously strategy-proof. The difference is that in an ascending auction, saying "No" guarantees that the participant will not buy. Under MPL, they might still end up buying at a lower price. A downside of the stopping rule is that it removes the possibility of "double switching," that is declining a lower price but accepting a higher price, which can be an additional indicator of miscomprehension.
} 
procedure to assign a treatment, so as to later evaluate the treatment's impact. ${ }^{4}$ But Onsite randomization makes it impossible to stratify this randomization, increasing the risk of imbalances and reducing statistical power. Researchers might therefore prefer Preassigned random prices, which can be stratified on variables available prior to elicitation. ${ }^{5}$ The cost is reduced transparency: it is harder for participants to verify that the randomization has been conducted as described.

Our second feature test compares Onsite to Preassigned randomization. We implement this using scratchcards. Under Onsite draws, the participant is given a scratchcard with 11 panels, each concealing a different price. They choose and scratch one of these to determine the price they will face. They are told in advance that once the price has been recorded, they will be able scratch the remaining panels to verify that the scratchcard was fair. Under Preassigned prices the participant is given a scratchcard with a single panel concealing a preassigned price. They are told that this price was chosen by a computer, and the enumerator does not know what it is, but of course they cannot verify this information.

To summarize, Onsite randomization has the advantage of transparency, but cannot be stratified. Preassigned randomization allows for stratification, but may lower trust in the mechanism.

\section{Information about the price distribution}

Our final design feature of interest is the amount of information given to participants about the price distribution. The standard approach is to use a uniform price distribution, and to inform the participant about this fact. This is simple to explain, even to participants unused to thinking about probabilities, and straightforward to implement transparently with familiar randomization devices.

There are good reasons for doing this. While in principle the incentive properties of the mechanism only depend on full support - that is, that all prices are drawn with some positive probability - in practice the distribution might matter. Mazar et al. (2013) find that shifting probability mass from the bottom to the top of the price distribution increases WTP in a BDM mechanism (see also Bohm et al. (1997)). One possibly explanation is that participants perceive salient features of the price

\footnotetext{
${ }^{4}$ Conditional on WTP, treatment is random and depends only on the price draw. Thus it is possible to estimate marginal treatment effects - treatment effects as a function of WTP - and use them to reconstruct other effects of interest (Heckman and Vytlacil, 2005). Burchardi et al. (2020b) use a selective trial to measure returns to fertilizer.

${ }^{5} \mathrm{An}$ intermediate approach that is easy to implement is to randomize the price after WTP has been elicited, but using a survey implement such as a tablet or mobile phone. We conjecture that this has more in common with Preassigned than Onsite randomization, because the participant has little insight into how the randomization was conducted. Another way to achieve stratification, which we do not explore, would be to randomize without replacement, for example through a public lottery draw, once WTP has been elicited from each member of a stratification group.
} 
distribution as informative about the true underlying value, or as hints as to what to bid. Alternatively, they might misunderstand the incentive properties, and approach the second-price mechanism like a first-price mechanism (Cason and Plott, 2014). If so, it is rational to bid below WTP and condition the bid on the price distribution. ${ }^{6}$

These findings suggest that few researchers will want to explicitly announce that the price distribution is nonuniform. But there might be good reasons not to provide full information about the price distribution. In particular, researchers might want to use a nonuniform price distribution, without providing this distracting information to participants. $^{7}$

Furthermore, it is not actually obvious which approach should be better for comprehension. Since the shape of the price distribution is irrelevant for incentives, taking pains to explain it to participants might be misleading, because doing so suggests that it is important and that participants should factor that into their decision. However, by not providing full information, we run the risk that participants come up with their own conjecture about the distribution, or worse, believe that somehow the price depends on their WTP.

Our final feature test, therefore, compares a Uniform price distribution, where the participants are informed about both the support and the distribution, to an Unstated distribution, where we only tell them its support. To operationalize the process, under Uniform we tell them that all of the prices are equally likely, and ask comprehension questions probing whether they understand what this means.

To summarize, Uniform prices have the advantage of transparency, and aim to control beliefs so as to avoid distorting WTP reports. The Unstated price distribution gives the researcher more freedom to use alternative distributions, as called for by their experimental design. It also has the potential advantage of not drawing too much attention to irrelevant information about prices.

\subsection{Treatments}

We have three design features of interest, but not all nine possible combinations are interesting or practical to test. We designed four experimental treatments, each of which changes one feature from the previous one. We can therefore test the effects of

\footnotetext{
${ }^{6}$ Note that if this is the underlying mechanism underbidding is also rational under uniform prices.

${ }^{7}$ We provide two examples. Burchardi et al. (2020a) elicit WTP for an education intervention. There were in fact only two possible prices, due to the design of the overarching impact evaluation. Participants were simply (truthfully) informed that the price was random, but not of its distribution or support. Burchardi et al. (2020b) use a selective trial to study returns to fertilizer. A particular issue in selective trials is that, with uniform prices, individuals with low WTP are unlikely to be treated, while individuals with high WTP are very likely to be treated, reducing statistical power. They instead use a bimodal price distribution with full support but 90 percent of its density split between zero and the maximum price, $P_{\max }$. Thus the probability of treatment, that is, $P \leq W T P$, is close to 50 percent for anyone with $W T P<P_{\max }$ (the probability is one if $W T P=P_{\max }$ ).
} 
each feature independently by comparing pairs of treatments. Experimental instructions can be found in Appendix C.

Treatment 1: BDM, Onsite, Uniform. Our benchmark treatment is a classic BDM implementation with Onsite, Uniform price randomization, similar to Berry et al. (2020). Participants simply state their value for the good, and prices are drawn after WTP elicitation from a uniform distribution.

Treatment 2: MPL, Onsite, Uniform. Relative to Treatment 1, Treatment 2 changes the reporting mode, from BDM to MPL.

Treatment 3: MPL, Preassigned, Uniform. Relative to Treatment 2, Treatment 3 changes the price randomization, from Onsite to Preassigned.

Treatment 4: MPL, Preassigned, Unstated. Finally, relative to Treatment 3, Treatment 4 changes the information we provide about the price distribution, from Uniform to Unstated.

Thus, comparing treatments 1 and 2 is informative about the effects of BDM versus MPL. Comparing treatments 2 and 3 is informative about Onsite versus Preassigned randomization. Comparing treatments 3 and 4 is informative about Uniform versus Unstated price distributions.

\subsection{Common design features}

\section{Price distribution}

In all treatments we kept the price distribution the same, a discrete uniform distribution over eleven possible prices. Participants were always informed of the distribution's support (i.e. what these possible prices were). We varied whether we informed them that all were equally likely (Uniform treatments) or not (Unstated treatment). ${ }^{8}$

\section{Price draw is independent of WTP}

If participants believe that their WTP report can somehow influence the price draw, the incentive properties of the mechanism are lost. This could be a concern when the price is drawn using a tablet or mobile phone or some other non-transparent randomizer.

\footnotetext{
${ }^{8}$ The standard BDM implementation uses a (near-) continuous price distribution, to maintain the incentive to report any value of WTP. We kept the discrete distribution throughout to maintain similarity across treatments. Thus, strictly speaking there is no incentive to report WTP in-between price increments. It is unclear whether this makes the basic incentive properties of the BDM easier or harder to understand. Some participants do state intermediate values, particularly in the Soap elicitation (for Voucher the vast majority state 1,400 UGX).
} 
To make it clear that the price was independent of WTP, we always revealed it using a pre-printed scratchcard, which we produced ourselves, using readily-purchased scratch stickers that we placed over pre-printed price cards. The scratchcard had either one (Preassigned treatments) or eleven (Onsite treatments) panels. For the Onsite treatments, the participant was told that they could first choose which panel to scratch to reveal their price, after which they would be allowed to scratch the remaining panels if they wanted (so that they could verify that the card was fair).

We believe the pre-printed scratchcards make it very clear that the price could not be influenced by WTP. One possible exception to this would be if the participant believed they could collude with the enumerator to find a lower price on the eleven-panel scratchcard. Our next design feature addresses this concern.

\section{Collusion-proofness}

An additional feature of our scratchcard implementation is collusion-proofness; in this case referring to collusion between the enumerator and participant to provide information about or distort the price draw. Besides lowering data quality, this is a potential concern in selective trials where the researcher wants treatment to be assigned correctly and fairly.

Collusion could come in two forms: a) the enumerator could tell the participant what the price will be prior to WTP elicitation; or b) the enumerator could distort the price by ensuring that a low price is drawn.

We rule out a) by using pre-printed scratchcards assigned to the respondent's unique ID. The enumerator did not know what price or what random order of prices was printed on the card. The enumerator was also required to write the final WTP on the card, and take a photograph of it, before any panels were scratched. This prevented them from revealing the price before WTP was elicited.

In the Preassigned treatments the enumerator cannot distort the price. In Public treatments they could do this by scratching several panels and reporting the lowest price as the true price. We rule this out by requiring them to photograph the card once again, after the first panel has been scratched.

The scratchcards turned out to be an extremely practical way to conduct the randomization, using only physical tools, while preventing collusion.

\section{Comprehension checks}

Our elicitation procedure always included a battery of comprehension checks, described in detail in section 4 . These were slightly adapted according to the 
treatment. Participants always had an opportunity to revise their WTP after the comprehension questions.

\section{Methodology}

\subsection{Sample and Randomization}

We conducted the experiment in Mbale District (Eastern Subregion Uganda, see map in Appendix Figure B.1). We randomly selected 7 villages, subject to a minimum population in the 2010 Census of 300 people or around 50 households, given an average household size of six. This criterion was to facilitate easily finding participants. Basic information about the sample villages is given in Table 1. All villages were in rural areas, the closest being about $7 \mathrm{~km}$ from Mbale city, while the furthest was around $19 \mathrm{~km}$ away. Field activities took place from 18-24 November 2016. Each village was visited for one day by a team of four enumerators, targeting 7-8 participants each per day.

Participants were mobilized on the day of the survey, by asking the village chairperson to gather around 35 people in the village that were willing to participate. We targeted 200 participants in total, and preassigned each participant ID to one of our four experimental treatments by a simple (non-stratified) randomization. Exactly 50 participants received each treatment. Prices, if preassigned, were randomized within each treatment.

The only descriptive information we collected was participant gender. To benchmark our sample, we report basic summary statistics on adult respondents for both the Eastern subregion we worked in, and for Uganda as a whole, in Appendix Table A.1. The data are taken from the 2013/2014 wave of the nationally representative Uganda National Panel Study (UNPS, part of the World Bank's Living Standards Measurement Study or LSMS). The results highlight that our experiment was conducted in a rural setting, with low levels of literacy and education, and large households. All of these characteristics are typical for Uganda as a whole, and the Eastern subregion in particular. Our participants therefore differ substantially from those in typical university-based lab studies, and might find the mechanisms we test less familiar and less easy to comprehend.

\subsection{Goods and optimal bidding}

We elicited participants' WTP for two goods. The first good was an induced-value voucher, redeemable for its face value in cash. We begin by demonstrating how the voucher works, and build trust, by giving the participant a voucher worth 100 UGX 
which they can immediately exchange for 100 UGX in cash. Then, we introduce the experimental voucher, which has a face value of 1,400 UGX. By way of comparison, this corresponds to $\$ 1.27$ at 2016 PPP, or around 30 percent of the daily agricultural wage in the region. ${ }^{9}$ We reproduce the voucher in Appendix Figure C.1.

The second good was a $600 \mathrm{~g}$ bar of blue soap of a brand commonly available in local markets. The typical market price for this product was 2,000 UGX.

There were 11 possible prices for each product. For the voucher, these were $\{0,200$, $400, \ldots, 2000\}$. It is a weakly dominant strategy to report WTP equal to the voucher's face value. ${ }^{10}$

For the soap, possible prices were $\{0,400,800, \ldots, 4000\}$. After conducting the WTP elicitation, we elicited participants' beliefs about the market price. Private values for the product might be heterogeneous, so any bid below market price could be optimal. We interpret bids strictly above the participant's perceived market price as plausibly non-optimal, but this is only suggestive. It could be optimal for a participant to bid above the market price if it is costly for them to obtain the product on the market, for example due to travel or effort costs.

\section{Comprehension checks}

We implemented several comprehension checks to test participants' understanding of the overall elicitation procedure and expose them to the possible consequences of their choices. We conjectured that this would induce them to change their behavior if the observed choice is a mistake and not a true statement of their preferences.

The comprehension check questions were asked both in the voucher and the soap round, although with some differences described below. The phrasing of each question is given in Appendix D.

In the voucher elicitation round, we asked two set of comprehension questions before WTP elicitation (Chart checks and Price checks) and two sets afterwards (Wouldyou-buy checks) and (Profit checks). In the soap elicitation round, only the Price checks and the Would-you-buy checks were asked. ${ }^{11}$ These checks are described below.

\footnotetext{
${ }^{9}$ The median adult agricultural daily wage in the $2013 / 14$ wave of the UNPS is 4,000 UGX, corresponding to around 4,500 UGX at 2016 prices.

${ }^{10}$ Since prices in the experiment are discrete, reporting WTP of one price increment below 1,400 UGX, i.e. 1,200 UGX, is also weakly dominant and we code it as optimal. In the BDM treatment, participants are free to submit any bid, so we code any bid between 1,200-1,400 UGX as optimal. Furthermore, one participant did not have enough cash with them to pay 1,400 UGX, we code them as bidding optimally if they do so given the liquidity constraint they faced.

${ }^{11}$ Each participant was asked each check question at least once. If the answer to the question was correct, the enumerator moved to the next question in the survey. In case of a wrong answer, the enumerator was supposed to re-explain the relevant feature of the procedure and to ask the check question again, for a maximum of three attempts. However, due to an implementation error, in some cases the enumerators did not ask the question again. In what follows, we therefore focus on the share
} 
After the checks were completed, the participants were asked whether they wanted to change their WTP. If they did, the elicitation procedure was repeated and a new WTP was recorded. In both the voucher round and the soap round, only 5 participants asked to change their initial WTP after the checks. In each case, only one of them ended up changing their WTP in the new elicitation.

\subsection{Pre-elicitation comprehension checks}

The first set of questions (Chart checks) was meant to test the participant's general understanding of the elicitation procedure, which had been explained by the enumerator during the introductory part of the survey. The participant was presented with three hypothetical scenarios, depicted in three charts. In each scenario a fictitious auction for a voucher worth 1,600 UGX was presented (i.e., different to the real 1,400 UGX voucher in the experiment), along with the profit or loss conditional on each possible random price draw, was presented. Participants had to indicate which chart corresponded to (i) the scenario with the highest likelihood of purchasing the voucher $\left(1^{\text {st }}\right.$ chart check) ${ }^{12}$ and (ii) the scenario with the highest likelihood of purchasing the voucher without suffering a monetary loss $\left(2^{\text {nd }}\right.$ chart check). ${ }^{13}$

In the second set of checks (Price checks), we tested the participants' understanding of the price distribution. Since the distribution of prices was not revealed to the participants in the MPL, Preassigned, Unstated treatment condition, participants in this treatment were not asked these questions. The participant had to (i) list the full set of possible prices that could be drawn (prices listed), ${ }^{14}$ and (ii) indicate whether, in their understanding, one of the 11 random prices was more likely to be drawn ( $1^{\text {st }}$ price check), or had no chance of being drawn ( $2^{\text {nd }}$ price check).

As shown in Panel A and Panel C of Table 2, the share of correct answers for each check question is high for each treatment arm. Overall, in the voucher round, $86 \%$ and 93\% of the participants answered the first and the second chart questions correctly, respectively. Price distribution comprehension is high in the voucher round. $94 \%$ of participants correctly listed all possible prices. $92 \%$ of participants correctly stated that there was no price that was more likely than the others. 93\% correctly stated that no price was guaranteed not to appear. Interestingly, performance on the latter two

\footnotetext{
of correct answers for the first attempt of the check questions.

12 "Among these possible answers, what is the answer where you have the highest chance of purchasing the card?"

13"Among these possible answers, what is the answer where you have the highest chance of purchasing the card without suffering a loss?"

${ }^{14}$ Mistakenly, 11 participants in the voucher and 36 in the soap treatments were not asked this question.
} 
questions is poorer in the soap round: only $74 \%$ answer each question correctly. ${ }^{15}$

\subsection{Post-elicitation comprehension checks}

After eliciting WTP, we tested whether participants understood the possible consequences of their choices.

First, in the would-you-buy checks. We presented two hypothetical random price draws, one higher (Buy at $p>$ WTP check) and one lower than their WTP (Buy at $p<W T P$ check), and and asked if they would be able to purchase in each case (the correct answers are no and yes respectively).

Next, in the voucher round only, we implemented the profit checks examining whether participants could calculate the monetary payoffs resulting from their choices. We did so by presenting them with some possible random price draws and asking them to calculate their payoff given their chosen WTP for the voucher, as well as conditional on alternative (hypothetical) WTP values. These questions were only asked if a participant's initial WTP was different than 1,400 UGX. In retrospect, it was an oversight not to also ask when WTP equalled 1,400 UGX. However, these checks do not appear to have affected our WTP data. All participants answered correctly, and only one participant changed their WTP after the post-elicitation checks.

Panel B of Table 2, shows the proportions of correct responses to the would-you-buy checks. For the first and second would-you-buy checks comprehension averages 91\% and $97 \%$ in the voucher round and $98 \%$ and $98 \%$ for the soap round.

\subsection{Analysis of comprehension}

In the Appendix we analyze comprehension in a regression framework. For voucher and soap separately, we compute average comprehension across the questions that were asked in all treatments (i.e., excluding the price checks which were not asked in the MPL, Preassigned, Unstated treatment). We then regress the average score on design features. Appendix Table A.2 presents the results. All regression coefficients are close to zero and precisely estimated. An F-test of the does reject the null of no difference between design features in any specification. In other words, we find no evidence of systematic differences in comprehension between design features. We conclude that comprehension was high across treatments, and design features do not seem to substantially affect it.

\footnotetext{
${ }^{15}$ We speculated that this might be due to experience of one price draw from the voucher round affecting beliefs about the price distribution. However, accuracy on the soap price checks is uncorrelated with the price drawn for the voucher.
} 


\section{Bidding behavior}

Figure 1 plots demand curves and the distribution of WTP for the voucher and the soap, by treatment.

For the voucher, it is easy to see from panels (a) and (b) that the vast majority of participants bid optimally, at 1,400 UGX. Moreover, strikingly, nobody bids above this level, which is a common issue in second-price mechanisms Kagel et al. (1987). There is little variation in demand between treatments.

For the soap, bidding is more heterogeneous. Some participants bid above the notional market price of 2,000 UGX and others bid below. To code (potentially) optimal bidding, we express their bid as a fraction of their belief of the actual market price ( $34 \%$ of participants believe the price is above 2,000 UGX). If this value is above 1 we consider the bid (potentially) suboptimal. Using this scaling, we plot demand and the WTP distribution in panels (c) and (d) (Appendix Figure B.2 provides the unscaled plots). The modal bid lies at 1, i.e., WTP equal to perceived market price. However a small number of bids are substantially higher, going up to five times the market price.

While it is hard to fully characterize optimal bidding for the soap product, it is notable that as with the voucher, the demand curves and distributions of WTP are very similar between treatments. This again suggests that the WTP elicited is very similar whichever mechanism is used.

Figure 2a plots the fraction of participants bidding optimally for vouchers, by treatment. Optimal bidding is high, averaging $86 \%$, and variation across treatments is generally small relative to sampling error. Figure $2 \mathrm{~b}$ plots potentially optimal bids (less than or equal to perceived market price) for soap. These lie in the $70-90 \%$ range with slightly more variation across treatments. Comparing voucher and soap bids, there are no obvious patterns in the variation across treatments.

Table 3 analyzes the three design features in a regression framework. We present linear probability regressions with optimal bids for vouchers or (potentially) optimal bids for soap as the dependent variable. We present estimates with no controls, village fixed effects, and village and enumerator fixed effects.

Our primary specification is column (3), which examines optimal voucher bidding by design feature, controlling for village and enumerator fixed effects. Optimal bidding in the benchmark treatment is $78 \%$, and the regression coefficients are small and precisely estimated. Our 95\% confidence intervals rule out differences across features larger than around 10 percentage points.

The specifications without enumerator fixed effects have larger point estimates but the differences across treatments are still small relative to standard errors, and not systematic, similar to what we saw in the figures. It is also notable that the enumerator fixed effects explain a large fraction of the outcome variation (R-squared in the voucher 
regression increases from 6.4 percent to 47.2 percent), suggesting that comprehension depends strongly on enumerator skill.

We conduct F-tests for the joint null of no differences in optimal bidding between design features. The $\mathrm{p}$-value on this test in our primary specification is 0.914 , i.e. we find no evidence of significant differences between features. The smallest such p-value, 0.089 , arises in the voucher specification with village fixed effects only.

We conclude that all four elicitation mechanisms, and hence all three design feature variations, resulted in both high and very similar levels of optimal bidding.

\subsection{Heterogeneity}

We only collect one demographic characteristic, which is participant gender. Appendix Table A.3 analyzes whether optimal bidding behavior differs by gender. Columns (1) and (3) pool all treatments and test for overall differences in optimal bidding for voucher and soap respectively. Columns (2) and (4) split out the features and interact with gender. Overall, women are slightly more likely than men to bid optimally for the voucher, but the difference is never more than 4.5 percentage points and never significant. The pattern is less consistent for soap and some point estimates are fairly large but again never significant. F-tests for the joint hypothesis of no differences across the eight feature $\times$ gender subgroups have $p$-values close to 1 . Realistically we are underpowered to detect design feature-specific differences by gender. That said, our findings do not suggest major heterogeneity along this dimension.

\subsection{Default}

A common implementation challenge in WTP studies is "default," or refusal to pay once the price has been realized (Maffioli et al., 2020). This seems to be a particular challenge when payment takes place some time after elicitation, for example when the good or service is offered on credit (Grimm et al., 2020), and when contract enforcement is weak.

Default may result from unanticipated liquidity or preference shocks that change the participant's WTP ex post. It may also reflect misunderstanding of the mechanism: if participants make mistakes, and end up committing to prices in excess of their true WTP, they may be more likely to default.

Default is a concern in part because if participants anticipate that they will be allowed to default, they may have less incentive to truthfully report their WTP.

In our study, payment took place immediately after WTP elicitation and enumerators were required to ensure participants had enough cash with them before 
recording their final WTP, so we did not observe any default. But our findings of high comprehension and optimal bidding suggest that, in implementations similar to ours, misunderstanding is not the most likely explanation of default behavior.

\section{Conclusion}

In this paper we experimentally test four variants of the classic Becker-DeGroot-Marschak mechanism for eliciting willingness to pay, with participants in rural Uganda. Our goal was to understand whether variation in design features led to differences in optimal bidding, measured by bidding for a voucher with known induced value, following Cason and Plott (2014).

We find that comprehension, and optimal bidding, are high and similar across treatments. We conclude that researchers can be confident in adopting the elicitation procedure best suited for their application, and readers can be confident that these procedures can elicit meaningful, truthful willingness to pay reports from participants. 


\section{References}

Akbarpour, M. AND S. Li (2020): “Credible Auctions: A Trilemma," Econometrica, $88,425-467$.

Andersen, S., G. W. Harrison, M. I. LAU, AND E. E. Rutström (2006): “Elicitation using multiple price list formats," Experimental Economics, 9, 383-405.

Ashraf, N., J. Berry, AND J. M. Shapiro (2010): "Can Higher Prices Stimulate Product Use? Evidence from a Field Experiment in Zambia," American Economic Review, 100, 2383-2413.

Ausubel, L. M. (2004): “An Efficient Ascending-Bid Auction for Multiple Objects," American Economic Review, 94, 1452-1475.

Becker, G. M., M. H. DeGroot, AND J. MARschaK (1964): “Measuring utility by a single-response sequential method," Behavioral Science, 9, 226-232.

Berkouwer, S. B. And J. T. DeAn (2020): "Credit and Attention in the Adoption of Profitable Energy Efficient Technologies in Kenya," Berkeley mimeo.

BERRY, J., G. FISCHER, AND R. GUITERAS (2020): “Eliciting and Utilizing Willingness to Pay: Evidence from Field Trials in Northern Ghana," Journal of Political Economy, $128,1436-1473$.

Berry, J. ANd P. MukherJee (2019): “Pricing Private Education in Urban India: Demand, Use, and Impact," Working paper.

BOHM, P., J. LindÉN, AND J. SONNEGÅRD (1997): “Eliciting Reservation Prices: Becker-DeGroot-Marschak Mechanismsvs.Markets," The Economic Journal, 107, 1079-1089.

BREBNER, S. AND J. SONNEMANS (2018): "Does the elicitation method impact the WTA/WTP disparity?" Journal of Behavioral and Experimental Economics, 73, 40-45.

Burchardi, K., J. De Quidt, S. Gulesci, And M. Sulaiman (2020a): “Credit Constraints and Demand for Remedial Education: Evidence From Tanzania," Working Paper.

Burchardi, K., J. DE QUIDT, B. Lerva, AND S. TRIPODI (2020b): “Credit Constraints and Capital Allocation in Agriculture: Theory and Evidence From Uganda," Working Paper. 
CAson, T. N. And C. R. Plott (2014): “Misconceptions and Game Form Recognition: Challenges to Theories of Revealed Preference and Framing," Journal of Political Economy, 122, 1235-1270.

Chassang, S., G. P. I Miquel, AND E. SNOWberg (2012): "Selective Trials: A Principal-Agent Approach to Randomized Controlled Experiments," American Economic Review, 102, 1279-1309.

COHEN, J. AND P. DupAs (2010): “Free Distribution or Cost-sharing? Evidence from a Randomized Malaria Prevention Experiment," Quarterly Journal of Economics, 125, $1-45$.

Cole, S., A. N. Fernando, D. STEIN, AND J. TOBACMAN (2020): “Field comparisons of incentive-compatible preference elicitation techniques," Journal of Economic Behavior E Organization, 172, 33-56.

DupAS, P. (2014): "Short-Run Subsidies and Long-Run Adoption of New Health Products: Evidence From a Field Experiment," Econometrica, 82, 197-228.

Fischer, G., D. KARlan, M. McConnell, AND P. RAfFler (2016): “To Charge or Not to Charge: Evidence from a Health Products Experiment in Uganda," Working paper.

(2019): "Short-term subsidies and seller type: A health products experiment in Uganda," Journal of Development Economics, 137, 110-124.

GRIMM, M. AND R. HARTWIG (2018): “Unblurring the Market for Vision Correction: A Willingness to Pay Experiment in Rural Burkina Faso," IZA DP No. 11929.

Grimm, M., L. Lenz, J. Peters, And M. Sievert (2020): “Demand for Off-Grid Solar Electricity: Experimental Evidence from Rwanda," Journal of the Association of Environmental and Resource Economists, 7, 417-454.

HanemanN, W. M. (1994): "Valuing the Environment Through Contingent Valuation," Journal of Economic Perspectives, 8, 19-43.

HeckMAN, J. J. AND E. Vytlacil (2005): “Structural Equations, Treatment Effects, and Econometric Policy Evaluation," Econometrica, 73, 669-738.

HofFMANN, B. (2018): "Do non-monetary prices target the poor? Evidence from a field experiment in India," Journal of Development Economics, 133, 15-32.

HoffmanN, V. (2009): "Intrahousehold Allocation of Free and Purchased Mosquito Nets," American Economic Review: Papers E Proceedings, 99, 236-241. 
Hoffmann, V., C. B. BARRett, And D. R. Just (2009): “Do Free goods Stick to Poor Households? Experimental Evidence on Insecticide Treated Bednets," World Development, 37, 607-617.

Kagel, J. H., R. M. HARSTAD, AND D. Levin (1987): "Information Impact and Allocation Rules in Auctions with Affiliated Private Values: A Laboratory Study," Econometrica, 55, 1275.

LeRVA, B. (2020): "Quantifying Externalities in Technology Adoption: Experimental Evidence from Ugandan Farmers," Working paper.

LI, S. (2017): “Obviously Strategy-Proof Mechanisms," American Economic Review, 107, 3257-3287.

Maffioli, A., D. McKenzie, And D. Ubfal (2020): “Estimating the Demand for Business Training: Evidence from Jamaica," World Bank Policy Research Working Paper No. 9415.

MaZar, N., B. Koszegi, AND D. Ariely (2013): "True Context-dependent Preferences? The Causes of Market-dependent Valuations," Journal of Behavioral Decision Making, 27, 200-208.

RUtSTRÖM, E. E. (1998): "Home-grown values and incentive compatible auction design," International Journal of Game Theory, 27, 427-441.

Yishay, A. B., A. Fraker, R. Guiteras, G. Palloni, N. B. Shah, S. Shirrell, AND P. WANG (2017): “Microcredit and willingness to pay for environmental quality: Evidence from a randomized-controlled trial of finance for sanitation in rural Cambodia," Journal of Environmental Economics and Management, 86, 121-140. 


\section{Tables and Figures}

\begin{tabular}{lcc}
\hline & Participants & Female \\
\hline Village 1 & 32 & .59 \\
Village 2 & 31 & .65 \\
Village 3 & 32 & .44 \\
Village 4 & 13 & .54 \\
Village 5 & 28 & .43 \\
Village 6 & 32 & .34 \\
Village 7 & 32 & .34 \\
Total & 200 & .48 \\
\hline
\end{tabular}

Table 1: Selected villages' characteristics 
Table 2: Proportion of correct answers to each comprehension check (first attempt)

\begin{tabular}{|c|c|c|c|c|c|}
\hline & Overall & BDM, Onsite, Uniform & MPL, Onsite, Uniform & MPL, Preassigned, Uniform & MPL, Preassigned, Unstated \\
\hline \multicolumn{6}{|c|}{ Panel A: Pre-elicitation checks, Voucher } \\
\hline $1^{s t}$ chart check & 0.86 & 0.86 & 0.88 & 0.88 & 0.82 \\
\hline $2^{\text {nd }}$ chart check & 0.93 & 0.86 & 1.00 & 0.94 & 0.90 \\
\hline Prices listed & 0.94 & 0.96 & 0.89 & 0.94 & 0.96 \\
\hline $1^{s t}$ price check & 0.92 & 0.94 & 0.90 & 0.92 & $\cdot$ \\
\hline $2^{\text {nd }}$ price check & 0.93 & 0.96 & 0.90 & 0.92 & . \\
\hline \multicolumn{6}{|c|}{ Panel B: Post-elicitation checks, Voucher } \\
\hline Buy at $p>W T P$ & 0.91 & 0.90 & 0.90 & 0.84 & 0.98 \\
\hline Buy at $p<W T P$ & 0.97 & 0.98 & 0.92 & 0.98 & 1.00 \\
\hline Avg. voucher & 0.92 & 0.92 & 0.91 & 0.92 & 0.93 \\
\hline \multicolumn{6}{|c|}{ Panel C: Pre-elicitation checks, Soap } \\
\hline Prices listed & 0.88 & 0.86 & 0.90 & 0.87 & 0.90 \\
\hline $1^{\text {st }}$ price check & 0.74 & 0.70 & 0.82 & 0.70 & . \\
\hline $2^{\text {nd }}$ price check & 0.74 & 0.70 & 0.82 & 0.70 & . \\
\hline \multicolumn{6}{|c|}{ Panel D: Post-elicitation checks, Soap } \\
\hline Buy at $p>W T P$ & 0.98 & 0.98 & 0.98 & 0.98 & 0.98 \\
\hline Buy at $p<W T P$ & 0.98 & 0.98 & 0.98 & 1.00 & 0.98 \\
\hline Avg. soap & 0.87 & 0.82 & 0.88 & 0.83 & 0.95 \\
\hline Avg. voucher + soap & 0.90 & 0.89 & 0.90 & 0.88 & 0.94 \\
\hline
\end{tabular}

The Table reports the share of correct answers to the first attempt of each check question, by Treatment assignment. In the " $1^{\text {st }}$ chart check", participants were asked to choose a chart describing the situation with the highest likelihood of buying the voucher. In the "2nd chart check", participants were asked to choose a chart describing the situation with the highest likelihood of buying the voucher, conditional on making no loss. In the "Prices listed check", participants had to list each possible price for the voucher/soap. In the " $1^{\text {st }}$ price check", participants were asked whether each price for the voucher/soap was equally likely to be draw. In the " $2^{\text {nd }}$ price check", participants were asked whether a price for the voucher/soap had no chance to be draw. In the "Buy at $p>$ WTP check" and "Buy at $p<W T P$ check", participants had to state whether they would have been able to buy the voucher/soap given a random price higher or lower than their initial WTP, respectively. 
Table 3: Optimal bidding for voucher and soap by design feature

\begin{tabular}{lcccccc}
\hline & $(1)$ & $(2)$ & $(3)$ & $(4)$ & $(5)$ & $(6)$ \\
& Voucher & Voucher & Voucher & Soap & Soap & Soap \\
\hline MPL & 0.120 & $0.128^{*}$ & -0.007 & -0.080 & -0.018 & -0.004 \\
& $(0.073)$ & $(0.073)$ & $(0.050)$ & $(0.086)$ & $(0.091)$ & $(0.080)$ \\
Preassigned price & -0.080 & -0.102 & 0.033 & $0.160^{* *}$ & 0.131 & 0.071 \\
& $(0.070)$ & $(0.068)$ & $(0.052)$ & $(0.079)$ & $(0.093)$ & $(0.086)$ \\
Unstated distribution & 0.100 & $0.106^{*}$ & -0.011 & -0.100 & -0.075 & -0.073 \\
& $(0.067)$ & $(0.061)$ & $(0.047)$ & $(0.075)$ & $(0.080)$ & $(0.080)$ \\
\hline Village FE & No & Yes & Yes & No & Yes & Yes \\
Enumerator FE & No & No & Yes & No & No & Yes \\
\hline F-test p-value & 0.157 & 0.089 & 0.914 & 0.213 & 0.434 & 0.734 \\
N & 200 & 200 & 200 & 200 & 200 & 200 \\
R-squared & 0.026 & 0.064 & 0.472 & 0.020 & 0.065 & 0.216 \\
BDM, Onsite, Uniform mean & 0.780 & 0.780 & 0.780 & 0.800 & 0.800 & 0.800 \\
\hline
\end{tabular}

Linear probability model. Robust standard errors in parentheses. ${ }^{*} p<0.1^{* *} p<0.05^{* * *} p<0.01$. Outcome in columns (1)-(3) is a dummy for optimal bidding in the voucher WTP elicitation. Outcome in columns (4)-(6) is a dummy for bidding no more than the perceived market price in the soap WTP elicitation. "MPL" is a dummy for all MPL treatments, "Preassigned price" is a dummy for all preassigned price treatments, "Unstated distribution" is a dummy for the treatment with unstated price distribution. "F-test p-value" corresponds to a test of the null hypothesis that the coefficients on all three dummies are zero. 
Figure 1: Demand curves and WTP distributions

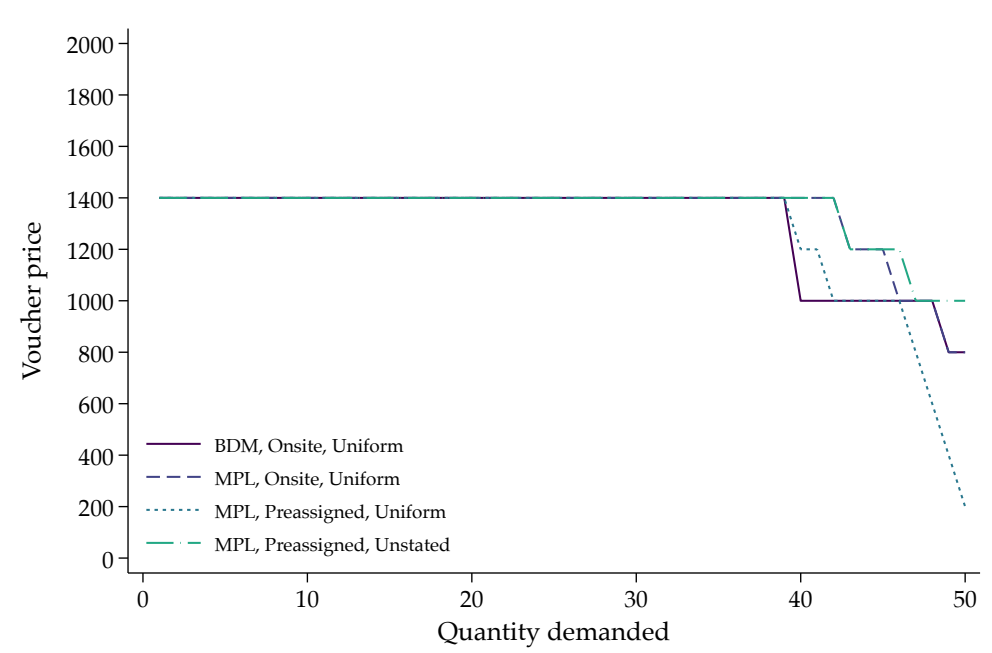

N

(a) Voucher demand

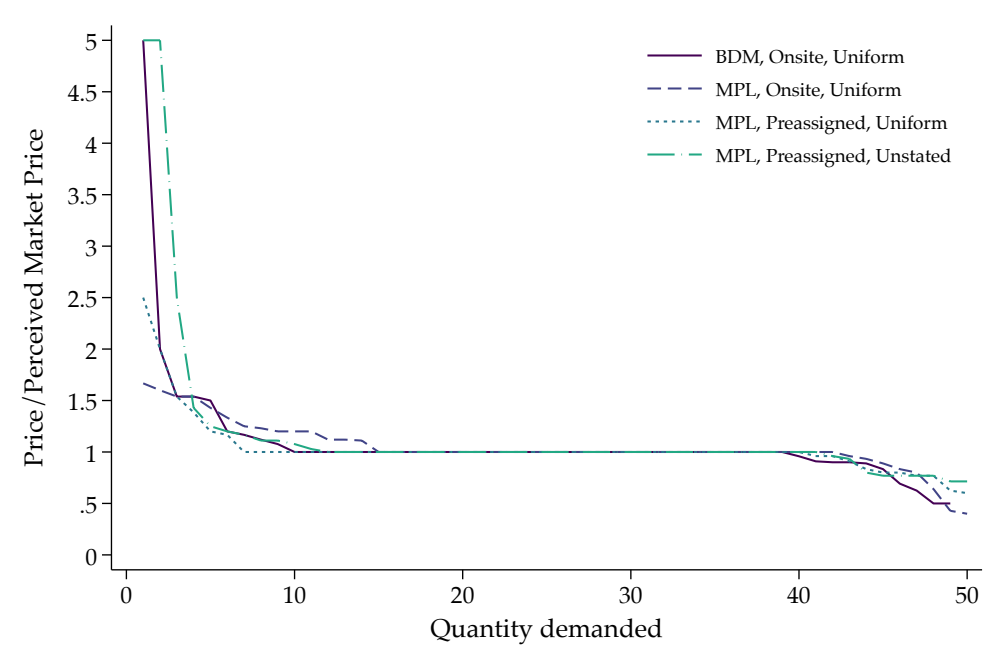

(c) Soap demand, scaled by perceived market price

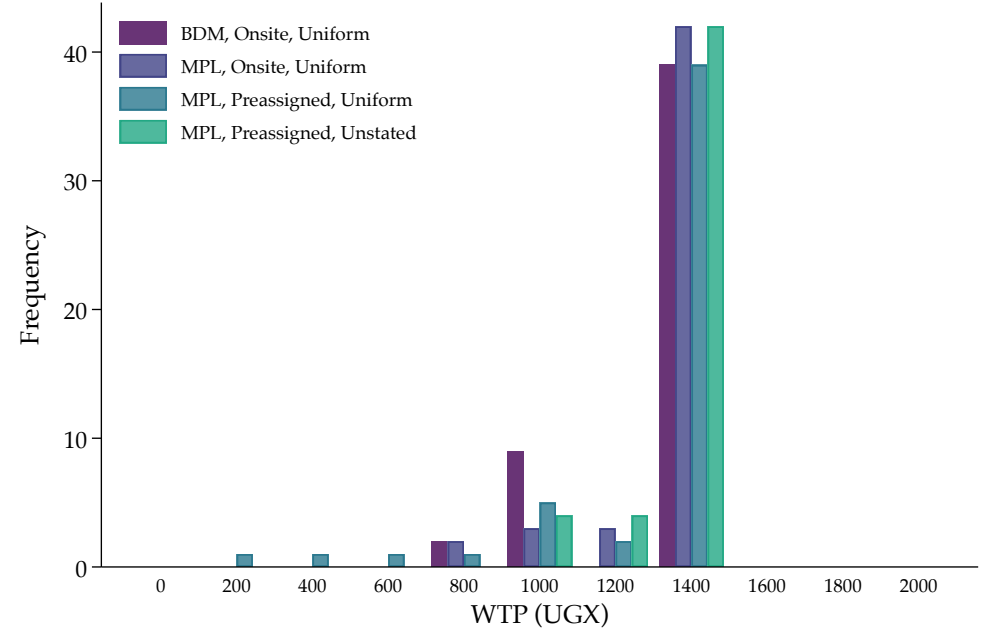

(b) Distribution of Voucher WTP

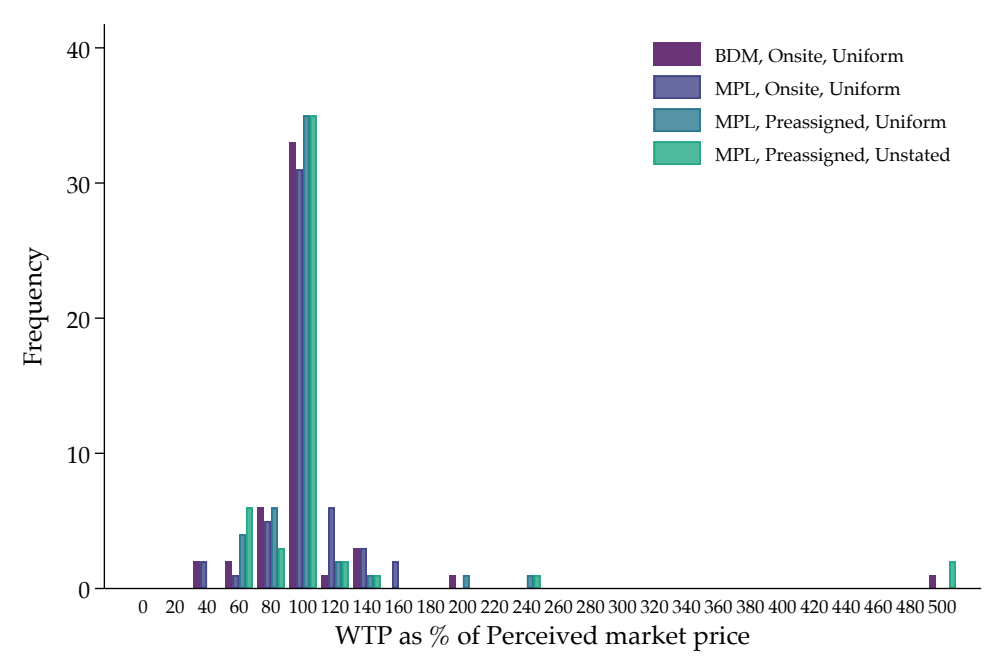

(d) Distribution of Soap WTP scaled by perceived market price

Note: in panels (b) and (d) WTP is rounded down to the nearest price increment when elicited via BDM 
Figure 2: Optimal bidding

(a) Voucher

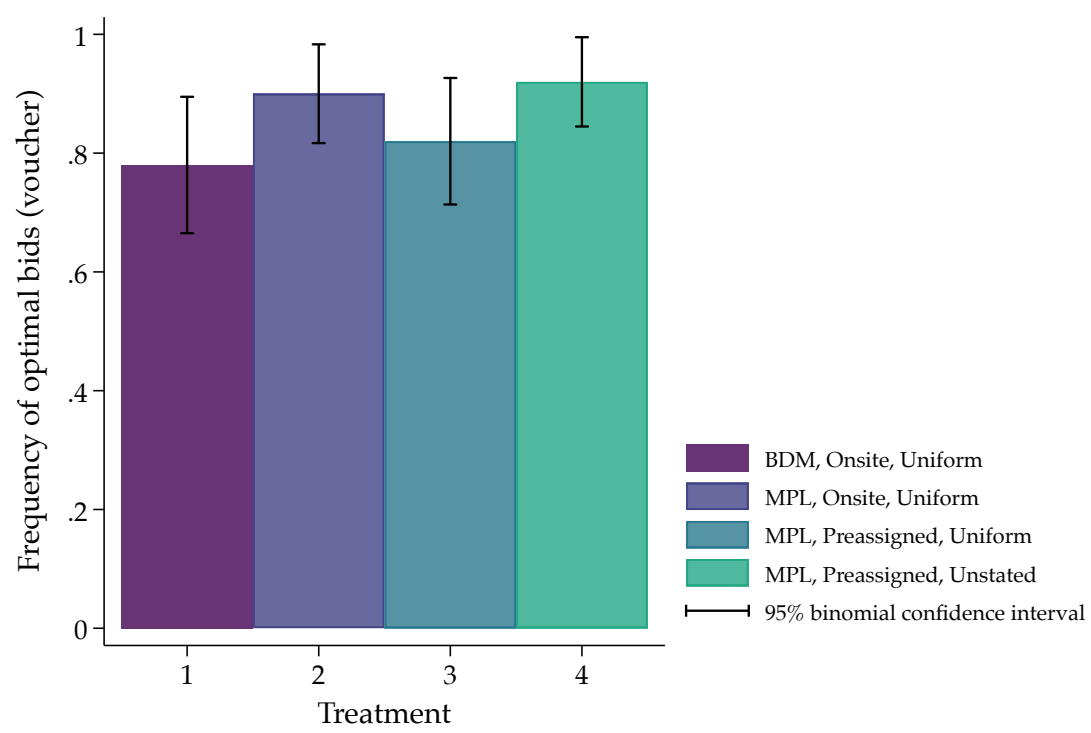

(b) Soap

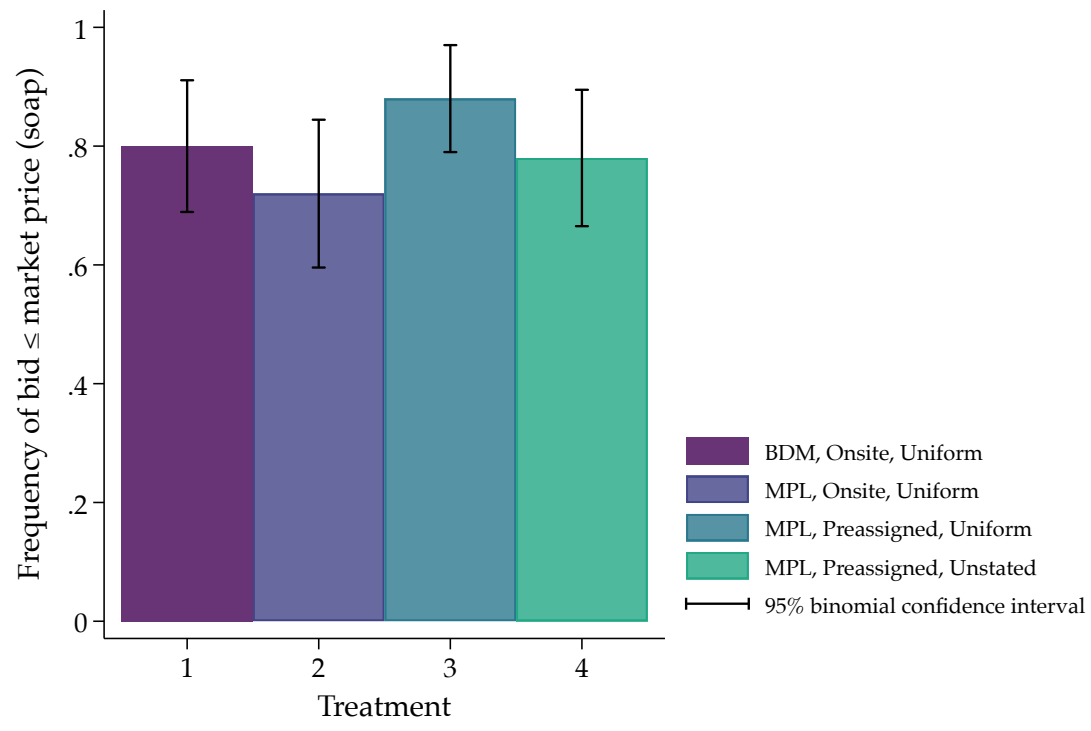




\title{
Web Appendix: Testing Willingness-to-Pay Elicitation
}

\section{Mechanisms in the Field: Evidence from Uganda}

\author{
Konrad Burchardi Jonathan de Quidt Selim Gulesci \\ Benedetta Lerva Stefano Tripodi
}

February 11, 2021

\section{A Appendix Tables}

Table A.1: Descriptive Statistics from Uganda National Panel Survey

\begin{tabular}{|c|c|c|c|c|}
\hline \multirow[b]{3}{*}{ Characteristic } & \multicolumn{2}{|c|}{ Eastern Subregion } & \multicolumn{2}{|c|}{ Uganda } \\
\hline & (1) & (2) & (3) & (4) \\
\hline & Mean & $\mathrm{N}$ & Mean & $\mathrm{N}$ \\
\hline \multirow[t]{2}{*}{ Age } & 37.72 & 1109 & 37.02 & 7863 \\
\hline & $(11.12)$ & & $(10.74)$ & \\
\hline \multirow[t]{2}{*}{ Female } & 0.54 & 1109 & 0.52 & 7863 \\
\hline & $(0.19)$ & & $(0.22)$ & \\
\hline \multirow[t]{2}{*}{ Years of Education } & 6.74 & 1109 & 6.71 & 7860 \\
\hline & $(3.38)$ & & $(3.63)$ & \\
\hline \multirow[t]{2}{*}{ Literacy } & 0.68 & 1109 & 0.74 & 7863 \\
\hline & $(0.33)$ & & $(0.32)$ & \\
\hline \multirow[t]{2}{*}{ Household Size } & 7.26 & 1109 & 6.74 & 7863 \\
\hline & $(3.27)$ & & $(3.32)$ & \\
\hline \multirow[t]{2}{*}{ Urban } & 0.11 & 1109 & 0.26 & 7863 \\
\hline & $(0.31)$ & & $(0.44)$ & \\
\hline
\end{tabular}

Notes: The table displays characteristics of the adult members (aged 18 or older) of the households sampled in the 2013/2014 wave of the Uganda National Panel Survey (UNPS). Age reports the age of the household member in completed years (Section 2, Question 8). Female is a dummy equal to 1 if the household member is female (Section 2, Question 3). Years of Education measures a household member's completed years of schooling (Section 4, Question 7 and 9). Literacy is a dummy equal to 1 if the household member can read and write in any language (Section 2, Question 4). Household Size counts the number of household members recorded in the household roster (Section 2). Urban is a dummy equal to 1 if the household resides in an urban area (Section 1A, Question 7). 
Table A.2: Average comprehension

\begin{tabular}{|c|c|c|c|c|c|c|}
\hline & \multicolumn{3}{|c|}{ Voucher } & \multicolumn{3}{|c|}{ Soap } \\
\hline & $\begin{array}{l}(1) \\
\text { Score }\end{array}$ & $\begin{array}{l}(2) \\
\text { Score }\end{array}$ & $\begin{array}{l}\text { (3) } \\
\text { Score }\end{array}$ & $\begin{array}{l}(4) \\
\text { Score }\end{array}$ & $\begin{array}{l}(5) \\
\text { Score }\end{array}$ & $\begin{array}{c}(6) \\
\text { Score }\end{array}$ \\
\hline MPL & $\begin{array}{c}0.006 \\
(0.031)\end{array}$ & $\begin{array}{c}0.037 \\
(0.031)\end{array}$ & $\begin{array}{c}-0.002 \\
(0.026)\end{array}$ & $\begin{array}{c}0.007 \\
(0.030)\end{array}$ & $\begin{array}{c}0.019 \\
(0.030)\end{array}$ & $\begin{array}{c}0.019 \\
(0.031)\end{array}$ \\
\hline Preassigned price & $\begin{array}{c}-0.000 \\
(0.031)\end{array}$ & $\begin{array}{c}-0.040 \\
(0.028)\end{array}$ & $\begin{array}{c}0.007 \\
(0.023)\end{array}$ & $\begin{array}{c}0.007 \\
(0.028)\end{array}$ & $\begin{array}{l}-0.020 \\
(0.024)\end{array}$ & $\begin{array}{l}-0.019 \\
(0.026)\end{array}$ \\
\hline Unstated distribution & $\begin{array}{c}0.013 \\
(0.030)\end{array}$ & $\begin{array}{c}0.010 \\
(0.028)\end{array}$ & $\begin{array}{l}-0.023 \\
(0.024)\end{array}$ & $\begin{array}{l}-0.007 \\
(0.025)\end{array}$ & $\begin{array}{c}0.001 \\
(0.023)\end{array}$ & $\begin{array}{c}-0.002 \\
(0.022)\end{array}$ \\
\hline Village FE & No & Yes & Yes & No & Yes & Yes \\
\hline Enumerator FE & No & No & Yes & No & No & Yes \\
\hline F-test p-value & 0.912 & 0.457 & 0.763 & 0.961 & 0.857 & 0.893 \\
\hline $\mathrm{N}$ & 200 & 200 & 200 & 200 & 200 & 200 \\
\hline R-squared & 0.002 & 0.113 & 0.350 & 0.001 & 0.026 & 0.116 \\
\hline BDM, Onsite, Uniform mean & 0.910 & 0.910 & 0.910 & 0.947 & 0.910 & 0.947 \\
\hline
\end{tabular}

Linear probability model. Robust standard errors in parentheses. ${ }^{*} \mathrm{p}<0.1^{* *} \mathrm{p}<0.05^{* * *} \mathrm{p}<0.01$. The outcome is the fraction of correct answers to the comprehension checks (excluding $1^{\text {st }}$ and $2^{\text {nd }}$ price check). "MPL" is a dummy for all MPL treatments, "Preassigned price" is a dummy for all preassigned price treatments, "Unstated distribution" is a dummy for the treatment with unstated price distribution. "F-test p-value" corresponds to a test of the null hypothesis that the coefficients on all three dummies are zero. 
Table A.3: Optimal bidding by gender

\begin{tabular}{|c|c|c|c|c|}
\hline & \multicolumn{2}{|c|}{ Voucher } & \multicolumn{2}{|c|}{ Soap } \\
\hline & $\begin{array}{c}(1) \\
\text { Voucher }\end{array}$ & $\begin{array}{c}(2) \\
\text { Voucher }\end{array}$ & $\begin{array}{c}(3) \\
\text { Soap }\end{array}$ & $\begin{array}{c}(4) \\
\text { Soap }\end{array}$ \\
\hline Female & $\begin{array}{c}0.006 \\
(0.037)\end{array}$ & $\begin{array}{c}0.045 \\
(0.085)\end{array}$ & $\begin{array}{c}0.042 \\
(0.057)\end{array}$ & $\begin{array}{c}-0.037 \\
(0.113)\end{array}$ \\
\hline MPL & & $\begin{array}{c}0.008 \\
(0.075)\end{array}$ & & $\begin{array}{c}-0.053 \\
(0.118)\end{array}$ \\
\hline Preassigned price & & $\begin{array}{c}0.051 \\
(0.071)\end{array}$ & & $\begin{array}{c}0.121 \\
(0.116)\end{array}$ \\
\hline Unstated distribution & & $\begin{array}{c}-0.011 \\
(0.078)\end{array}$ & & $\begin{array}{c}-0.167 \\
(0.107)\end{array}$ \\
\hline MPL $\times$ female & & $\begin{array}{c}-0.028 \\
(0.104)\end{array}$ & & $\begin{array}{c}0.093 \\
(0.160)\end{array}$ \\
\hline Preassigned $\times$ female & & $\begin{array}{l}-0.039 \\
(0.110)\end{array}$ & & $\begin{array}{c}-0.106 \\
(0.148)\end{array}$ \\
\hline Unstated $\times$ female & & $\begin{array}{c}-0.003 \\
(0.110)\end{array}$ & & $\begin{array}{c}0.228 \\
(0.144)\end{array}$ \\
\hline Village FE & Yes & Yes & Yes & Yes \\
\hline Enumerator FE & Yes & Yes & Yes & Yes \\
\hline F-test $p$-value & & 0.991 & & 0.800 \\
\hline $\mathrm{N}$ & 200 & 200 & 200 & 200 \\
\hline R-squared & 0.472 & 0.474 & 0.214 & 0.229 \\
\hline Mean outcome in omitted group & 0.821 & 0.680 & 0.792 & 0.800 \\
\hline
\end{tabular}

Linear probability model. Robust standard errors in parentheses. ${ }^{*} \mathrm{p}<0.1^{* *} \mathrm{p}<0.05^{* * *}$ $\mathrm{p}<0.01$. Outcome in columns (1)-(2) is a dummy for optimal bidding in the voucher WTP elicitation. Outcome in columns (3)-(4) is a dummy for bidding no more than the perceived market price in the soap WTP elicitation. "Female" is a dummy for female participants. "MPL" is a dummy for all MPL treatments, "Preassigned price" is a dummy for all preassigned price treatments, "Unstated distribution" is a dummy for the treatment with unstated price distribution. "F-test p-value" corresponds to a test of the null hypothesis that the coefficients on all three dummies, and their interactions with "Female," are zero. 


\section{B Appendix Figures}

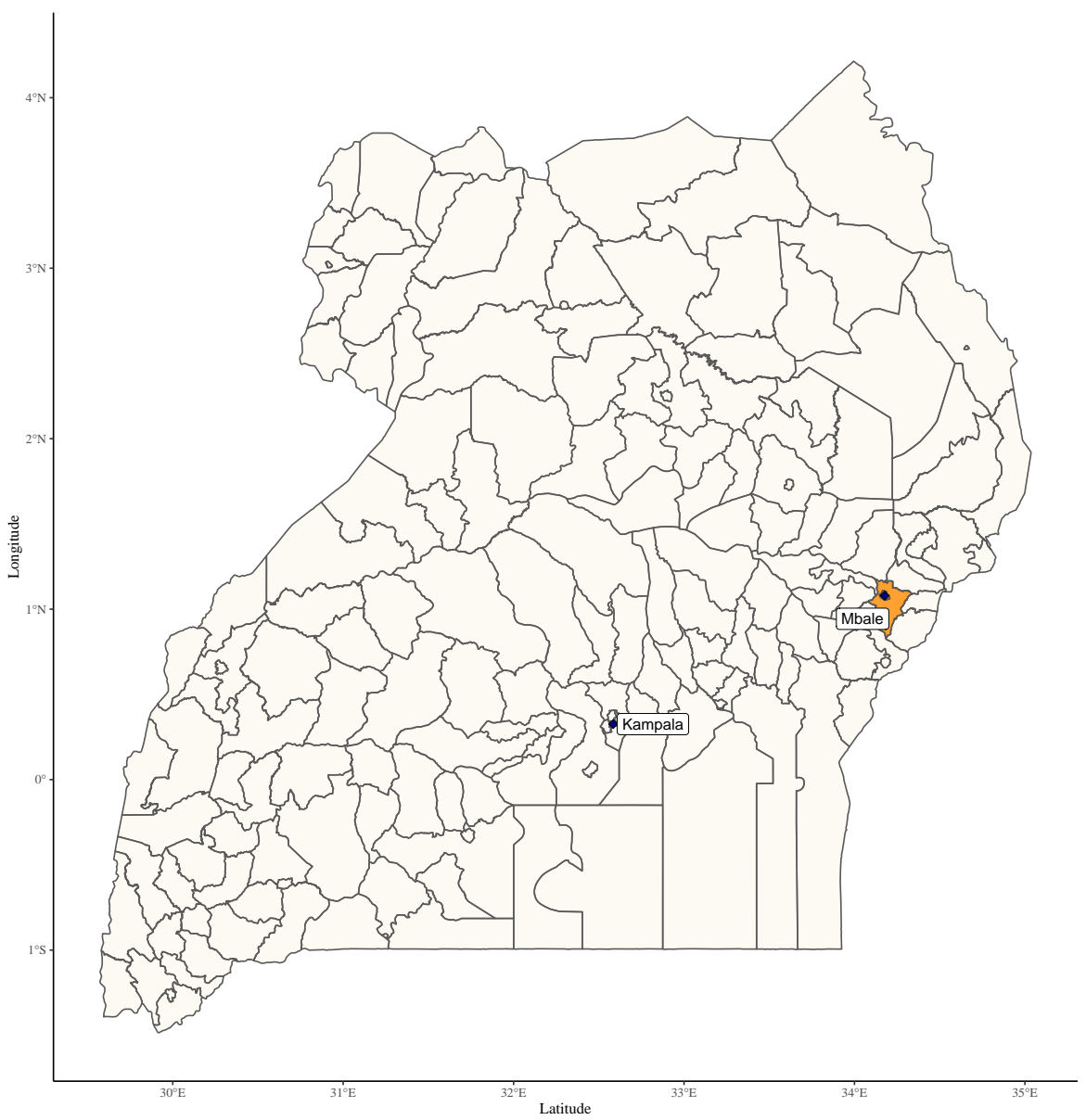

Figure B.1: Map of study area.

Figure shows Mbale district relative to Uganda as a whole. 
Figure B.2: Soap demand curve and WTP distribution (unscaled)

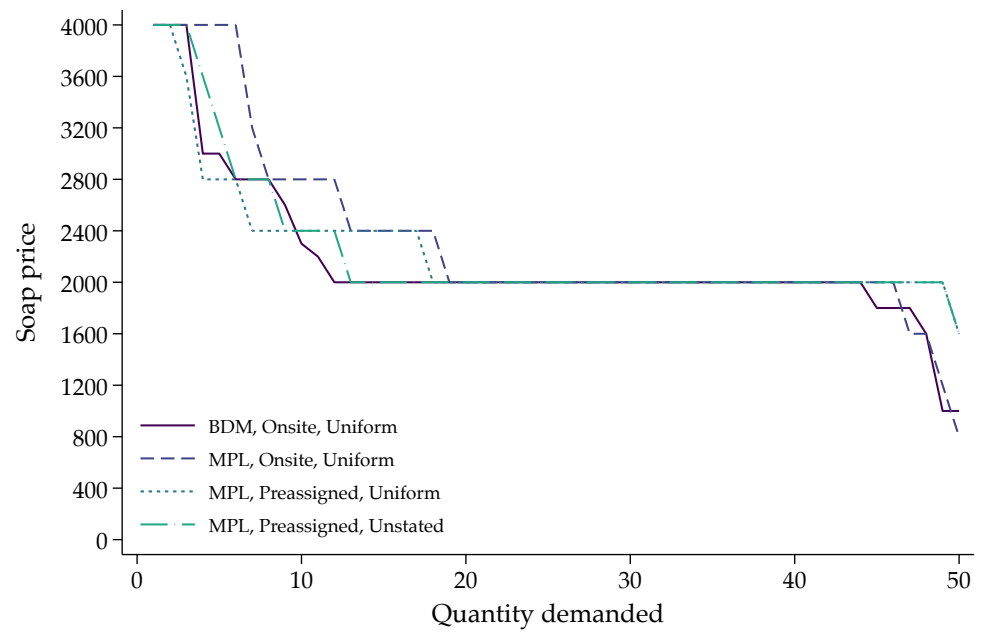

(a) Soap demand (unscaled)

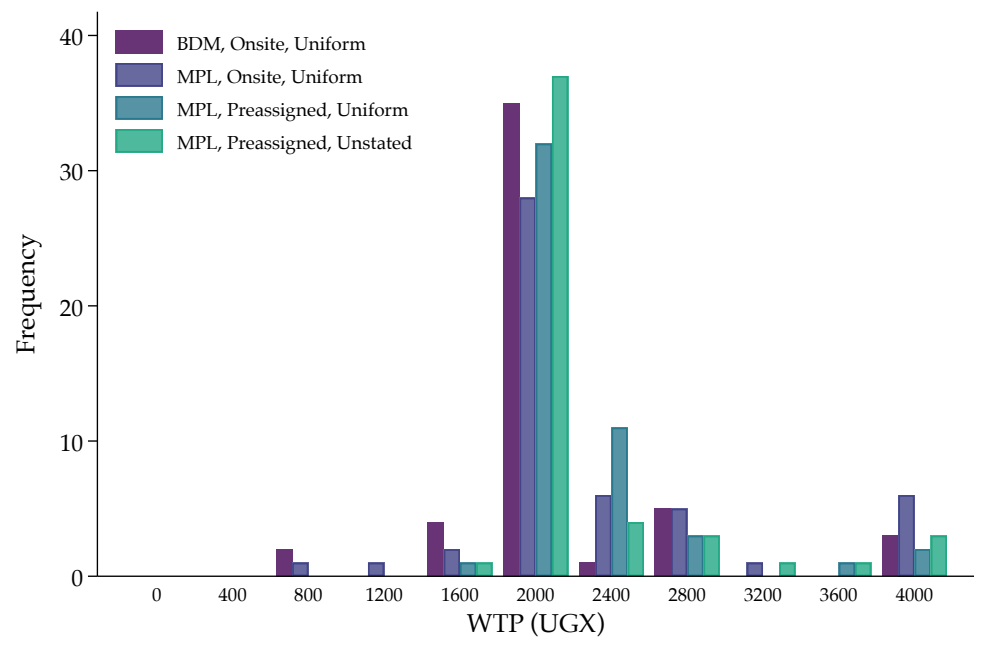

(b) Distribution of Soap WTP (unscaled)

Note: in panel (b) WTP is rounded down to the nearest price increment when elicited via BDM 


\section{WTP elicitation instructions}

The instructions we gave are the following. In case there were differences between treatments, these differences are presented.

"The purpose of the experiment that will follow is to understand what is your Willingness to Pay for some goods. Please, keep in mind that there are no right or wrong answers. We will just as some questions to check your understanding.

Before moving on with the explanation, I would like you to think about the following situation: imagine you need to buy a box of sugar. Usually, when you enter in the shop you might already have in mind what you would be willing to pay for the sugar. In other words, you might think about what is the maximum price at which you would still buy the sugar. Since you do not know what the actual price of sugar is, the price you think about is usually your own valuation. After you enter in the shop, you observe the actual price of sugar and you decide whether to buy the sugar or not. Your decision will depend on the actual price of the sugar: if the price is higher than your valuation, you will not buy the sugar. If instead the price is equal or lower than your valuation, you will buy the sugar.

This sale round is similar to the example we made before. This voucher is worth 1,400 UGX and has no value outside the experiment. Please, imagine a situation where you want to buy this voucher. We will ask you to form your own valuation about the maximum price you would pay for this voucher.

1. MPL, Onsite, Uniform, MPL, Preassigned, Uniform, MPL, Preassigned, Unstated: After you have thought about this price, we will present you a list of 11 possible prices for this voucher and we will ask you whether you would be willing to pay each possible price for it. The prices range from 0 to 2,000 UGX and increase by 200 UGX each time. For example, we will ask "Would you buy the voucher for 1,000 UGX?"; "Would you buy the voucher for 1,200 UGX?"; and so on.

2. BDM, Onsite, Uniform: The price you state will not be the price you will pay for it. Indeed, the actual price will be determined in the following way.

You will be given

1. MPL, Onsite, Uniform: a paper with the same prices we presented you, covered by some scratch stickers.

2. MPL, Preassigned, Uniform, MPL, Preassigned, Unstated: a scratchcard with your price.

3. BDM, Onsite, Uniform: a scratchcard with 11 prices on it, covered by some scratch stickers. 
This price might be $0,200,400, \ldots$, up to 2,000 Shillings.

1. BDM, Onsite, Uniform, MPL, Onsite, Uniform: Each of these values appears exactly once on your scratchcard. The prices are shuffled, so that they are in a random order on the paper and the enumerator does not know the order of the prices on the sheet. In each box there is one price, but it is not possible to know this price before scratching. You are required to choose only one of these prices and to scratch the one you have chosen.

2. MPL, Preassigned, Unstated: The price has been randomly selected by the computer and enumerator does not know it

3. MPL, Preassigned, Uniform: Each of these values is equally likely to be on your scratchcard. The price has been randomly selected by the computer and enumerator does not know it.

If the maximum price you agreed to pay is higher than the price on the scratch card, you will purchase the voucher paying the price you scratched. If the maximum price you agreed to pay is lower than the price on the scratch card, you will not purchase the voucher. Given the mechanism, it is in your best interest to state the true maximum price you are willing to pay for the voucher, since you will never pay more and you could end up paying less. Moreover, the price you stated will affect your chance of purchasing the voucher, but might not be the price you will actually pay.

1. BDM, Onsite, Uniform, MPL, Onsite, Uniform: After you have scratched the paper and after the interviewer has recorded the price on the tablet, you might scratch all the remaining prices in order to verify the other prices.

At the end of the experiment, in case your Willingness to Pay is higher than the scratched price, (so that you managed to buy the voucher) you will purchase the card. If you want, we will repurchase the card from you for its value."

Instructions for the soap round were similar to those used in the voucher round and presented the same across-treatments differences: Please imagine you want to buy a bar of soap.

1. MPL, Onsite, Uniform, MPL, Preassigned, Uniform, MPL, Preassigned, Unstated: This sale round is similar to the voucher round we made before: we will ask you to form your own valuation about the maximum price you would pay for this soap. After you have thought about this price, we will present you a list of 11 possible prices for the soap and we will ask you whether you would be willing to pay each possible price for it. The prices range from 0 UGX to 4000 UGX and increase by 400 UGX each time. For example we will ask "Would you buy the soap for 1200 UGX?"; "Would you buy the soap for 1600 UGX?"; and so on. 
2. BDM, Onsite, Uniform: This sale round is similar to the voucher round we made before: we will ask you to state the maximum price you would pay for this bar of soap, but the price you state will not be the price you will pay for it. Indeed, the actual price paid will be determined in the following way

Then you will be given

1. MPL, Onsite, Uniform: a paper with the same prices we presented to you covered with a scratch card

2. MPL, Preassigned, Uniform, MPL, Preassigned, Unstated: a scratch card with your price like this one

3. BDM, Onsite, Uniform: a scratch card with 11 prices on it, like this one

This price may be $0,400,800, \ldots$, up to 4000 Shillings

1. BDM, Onsite, Uniform, MPL, Onsite, Uniform: and each of these values appears exactly once on your scratch card The prices are shuffled, so that they are in a random order on the paper. In each box there is one price, but it is not possible to know what this price is before scratching and enumerator does not not know the order of the prices on the sheet. You are required to choose only one of these prices and to scratch the one you have chosen

2. MPL, Preassigned, Unstated: The price has been randomly selected by the computer and enumerator does not know it.

3. MPL, Preassigned, Uniform: and each of these values is equally likely to be on your scratch card. The price has been randomly selected by the computer and enumerator does not know it.

If the maximum price you agreed to pay is higher than the price on the scratch card, you will purchase the soap paying the price you scratched. If the maximum price you agreed to pay is lower than the price on the scratch card, you will not purchase the soap. Given the mechanism, it is in your best interest to state the true maximum price you are willing to pay for the soap, since you will never pay more and you could end up paying less. Moreover, the price you stated will affect your chance of purchasing the soap but might not be the price you will actually pay. After you have scratched the paper and after the interviewer has recorded the price on the tablet, you might scratch all the remaining prices in order to verify the other prices.

At the end of the experiment, in case your Willingness to Pay is higher than the scratched price, (so that you managed to buy the soap) you will purchase the soap. 
The other main survey difference between treatments relates to the elicitation questions. We tested 3 treatment variants that use a Multiple Price List elicitation procedure (MPL, Onsite, Uniform, MPL, Preassigned, Uniform, MPL, Preassigned, Unstated) and 1 treatment with classic BDM (BDM, Onsite, Uniform) elicitation procedure. In the former case, the respondent was asked the following battery of questions during the voucher round:

1. Would you buy the voucher for 0 Shillings (for free)?

2. Are you sure you don't want to buy the voucher even if it for free? ${ }^{16}$

3. Does this mean that you don't want to purchase the voucher at all? ${ }^{17}$

4. Would you buy the voucher for 200 Shillings? ${ }^{18}$

5. Are you sure you do not want to buy the voucher for 200 Shillings? ${ }^{19}$

6. Would you buy the voucher for 400 Shillings?

7. Are you sure you do not want to buy the voucher for 400 Shillings?

8. Would you buy the voucher for 600 Shillings?

9. Are you sure you do not want to buy the voucher for 600 Shillings?

10. Would you buy the voucher for 800 Shillings?

11. Are you sure you do not want to buy the voucher for 800 Shillings?

12. Would you buy the voucher for 1000 Shillings?

13. Are you sure you do not want to buy the voucher for 1000 Shillings?

14. Would you buy the voucher for 1200 Shillings?

15. Are you sure you do not want to buy the voucher for 1200 Shillings?

16. Would you buy the voucher for 1400 Shillings?

17. Are you sure you do not want to buy the voucher for 1400 Shillings?

18. Would you buy the voucher for 1600 Shillings?

19. Are you sure you do not want to buy the voucher for 1600 Shillings?

\footnotetext{
${ }^{16}$ If No.1 $=$ No

${ }^{17}$ If No. $2=$ Yes

${ }^{18}$ If No.1 = Yes

${ }^{19}$ If No.4 = No. In case the answer to this question was "No", the enumerator was supposed to ask the previous question again. The following questions followed the same skip rule.
} 
20. Would you buy the voucher for 1800 Shillings?

21. Are you sure you do not want to buy the voucher for 1800 Shillings?

22. Would you buy the voucher for 2000 Shillings?

23. Are you sure you do not want to buy the voucher for 2000 Shillings? ${ }^{20}$

The rule we followed was to always confirm that the subject did not want to buy the voucher in case of a negative answer. In case of confirmation of the negative answer, the tablet automatically registered the highest price at which respondent agreed to purchase the voucher as his Willingness to Pay for it. If the subject refused to purchase the voucher for free, the experiment would have ended. However, no one refused to buy the voucher for free. The procedure for BDM, Onsite, Uniform was shorter: we began by asking whether the subject was willing to purchase the voucher ("Do you want to buy this voucher?" and then we directly asked "What is the maximum price you would pay for this voucher?". Again, if respondent was not willing to purchase the voucher at all, the experiment would have stopped.

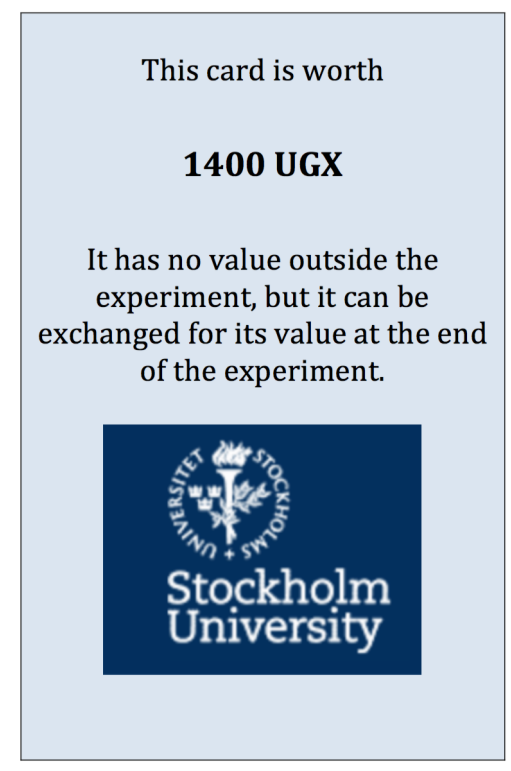

Figure C.1: Voucher for 1,400 UGX used in the experiment

\footnotetext{
${ }^{20}$ The battery of elicitation questions for the soap has been adjusted to reflect soap price range.
} 


\section{Comprehension checks}

The following Section reports the exact wording of the comprehension checks for the voucher elicitation round. In the soap section, we only performed the Price Distributions checks and the Buy/Not buy checks, since profits were not well-defined for the soap. The wording of the questions was the same, with only difference that, for the buy/not buy checks, the WTP increment was 400 Ugandan Shillings instead of 200.

(a) Chart Checks: after participant observed the three charts (reproduced in Figures D.2, D.3, and D.4), we asked

(1) Please, look at these charts. These charts present different possible answers you might give to the question "What is Willingness to Pay for this voucher?". Among these possible answers, what is the answer where you have the highest chance of purchasing the card?

(2) Please, look again at these charts. Among the situations presented, what is the situation where you have the highest chance of purchasing the card without suffering a loss? Remember that you will suffer a loss if you buy the voucher paying a price that is above its value. On the contrary, you will gain a profit if the price you pay for the voucher is less than its value.

(b) Price Distribution Checks:

(1) Did respondent list ALL the possible prices that might appear?

(2) Do you think there is one price, among those that can be on the scratch cards, that can appear more than once in the sheet? (BDM, Onsite, Uniform; MPL, Onsite, Uniform)

(3) Do you think there is one price, among those that can be on scratch cards, that has no chance to appear on the sheet? (BDM, Onsite, Uniform; MPL, Onsite, Uniform)

(4) Do you think there is one price, among those that can be on your scratch card, that has more chance than others to be on the card? (MPL, Preassigned, Uniform)

(5) Do you think there is one price, among those that can be on you scratch card, that has no chance to appear on the card? (MPL, Preassigned, Uniform)

(c) Buy/Not buy Checks:

(1) Please tell me, if the price on the scratch card turns out to be WTP +200 , what will happen? 
(2) Please tell me, if the price on the scratch card turns out to be WTP - 200, what will happen?

The Profit Checks were related to the initial WTP that the respondent stated. We therefore have the following scenarios:

(a) WTP $<200$ : call $x$ the subject's Willingness to Pay such that $0 \leq x<200$

(1) Remember that your offer was $x$ Shillings. Please suppo sethe price on the scratch card turns out to be 200 Shillings. What would your profit be in this case, if you decide to return the card at the end of the experiment?

(2) Imagine that instead of $x$ Shillings, you offered 400 Shillings and the price on your scratch card is still 200 Shillings. Can you please tell me what would your profit be in this case, if you decide to return the card at the end of the experiment?

(3) Remember that your offer was $x$ Shillings. Please suppose the price on the scratch card turns out to be 800 Shillings. What would your profit be in this case, if you decide to return the card at the end of the experiment?

(4) Imagine that instead of $x$ Shillings, you offered 1000 Shillings and the price on the scratch card is still 800 Shillings. Can you please tell me what would your profit be in this case, if you decide to return the card at the end of the experiment??

(5) Remember that your offer was $x$ Shillings. Please suppose the price on the scratch card turns out to be 1200 Shillings. What would your profit be in this case, if you decide to return the card at the end of the experiment?

(6) Imagine that instead of $x$ Shillings, you offered 1400 Shillings and the price on the scratch card is still 1200 Shillings. Can you please tell me what would your profit be in this case, if you decide to return the card at the end of the experiment?

(b) $200 \leq W T P<800$ : call $x$ the subject's Willingness to Pay such that $200 \leq x<$ 800

(1) Remember that your offer was $x$ Shillings. Please suppose the price on the scratch card turns out to be 200 Shillings. What would your profit be in this case, if you decide to return the card at the end of the experiment?

(2) Remember that your offer was $x$ Shillings. Please suppose the price on the scratch card turns out to be 800 Shillings. What would your profit be in this case, if you decide to return the card at the end of the experiment? 
(3) Imagine that instead of $x$ Shillings, you offered 1000 Shillings and the price on the scratch card is still 800 Shillings. Can you please tell me what would your profit be in this case, if you decide to return the card at the end of the experiment??

(4) Remember that your offer was $x$ Shillings. Please suppose the price on the scratch card turns out to be 1200 Shillings. What would your profit be in this case, if you decide to return the card at the end of the experiment?

(5) Imagine that instead of $x$ Shillings, you offered 1400 Shillings and the price on the scratch card is still 1200 Shillings. Can you please tell me what would your profit be in this case, if you decide to return the card at the end of the experiment?

(c) $800 \leq W T P<1200$ : call $x$ the subject's Willingness to Pay such that $800 \leq x<$ 1200

(1) Remember that your offer was $x$ Shillings. Please suppose the price on the scratch card turns out to be 200 Shillings. What would your profit be in this case, if you decide to return the card at the end of the experiment?

(2) Remember that your offer was $x$ Shillings. Please suppose the price on the scratch card turns out to be 800 Shillings. What would your profit be in this case, if you decide to return the card at the end of the experiment?

(3) Remember that your offer was $x$ Shillings. Please suppose the price on the scratch card turns out to be 1200 Shillings. What would your profit be in this case, if you decide to return the card at the end of the experiment?

(4) Imagine that instead of $x$ Shillings, you offered 1400 Shillings and the price on the scratch card is still 1200 Shillings. Can you please tell me what would your profit be in this case, if you decide to return the card at the end of the experiment?

(d) WTP = 1200: call $x$ the subject's Willingness to Pay such that $x=1200$

(1) Remember that your offer was $x$ Shillings. Please suppose the price on the scratch card turns out to be 200 Shillings. What would your profit be in this case, if you decide to return the card at the end of the experiment?

(2) Remember that your offer was $x$ Shillings. Please suppose the price on the scratch card turns out to be 800 Shillings. What would your profit be in this case, if you decide to return the card at the end of the experiment? 
(3) Remember that your offer was $x$ Shillings. Please suppose the price on the scratch card turns out to be 1200 Shillings. What would your profit be in this case, if you decide to return the card at the end of the experiment?

(e) $W T P=1600$ : call $x$ the subject's Willingness to Pay such that $x=1600$

(1) Remember that your offer was $x$ Shillings. Please suppose the price on the scratch card turns out to be 1600 Shillings. What would your profit be in this case, if you decide to return the card at the end of the experiment?

(f) WTP = 1800: call $x$ the subject's Willingness to Pay such that $x=1800$

(1) Remember that your offer was $x$ Shillings. Please suppose the price on the scratch card turns out to be 1800 Shillings. What would your profit be in this case, if you decide to return the card at the end of the experiment?

(g) WTP = 2000: call $x$ the subject's Willingness to Pay such that $x=2000$

(1) Remember that your offer was $x$ Shillings. Please suppose the price on the scratch card turns out to be 2000 Shillings. What would your profit be in this case, if you decide to return the card at the end of the experiment?

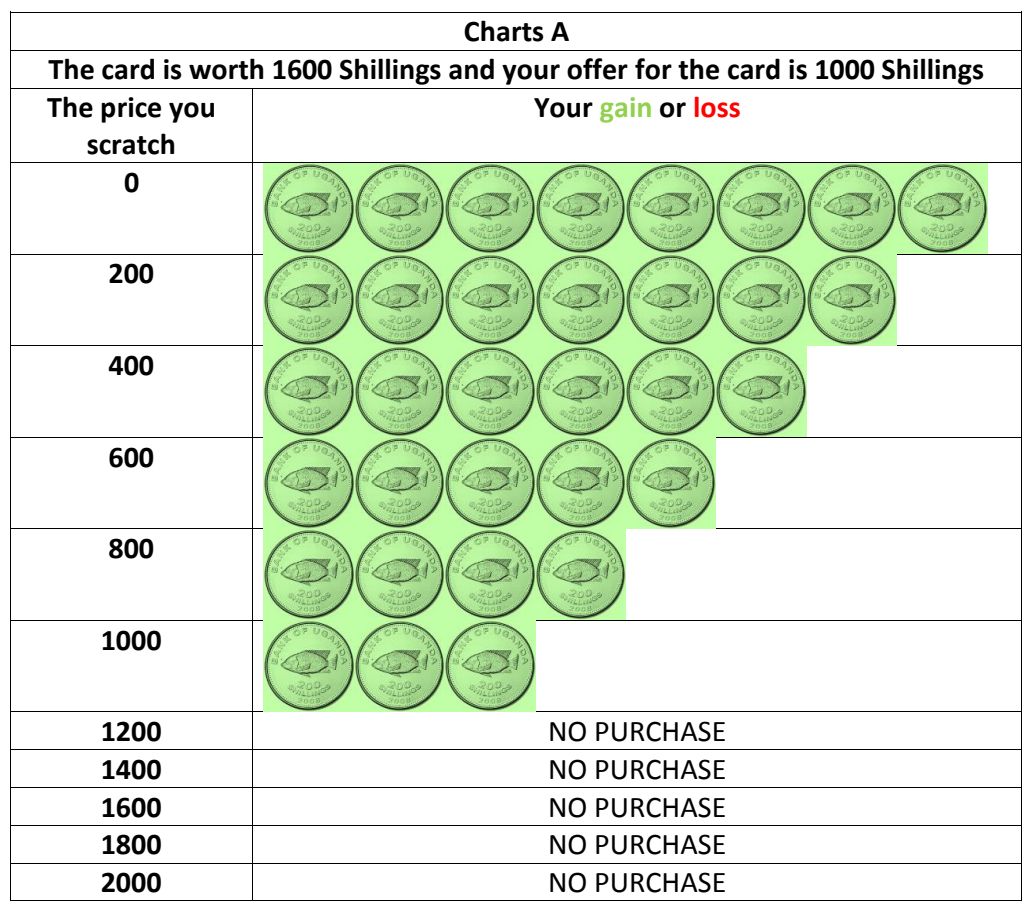

Figure D.2: Chart check A 


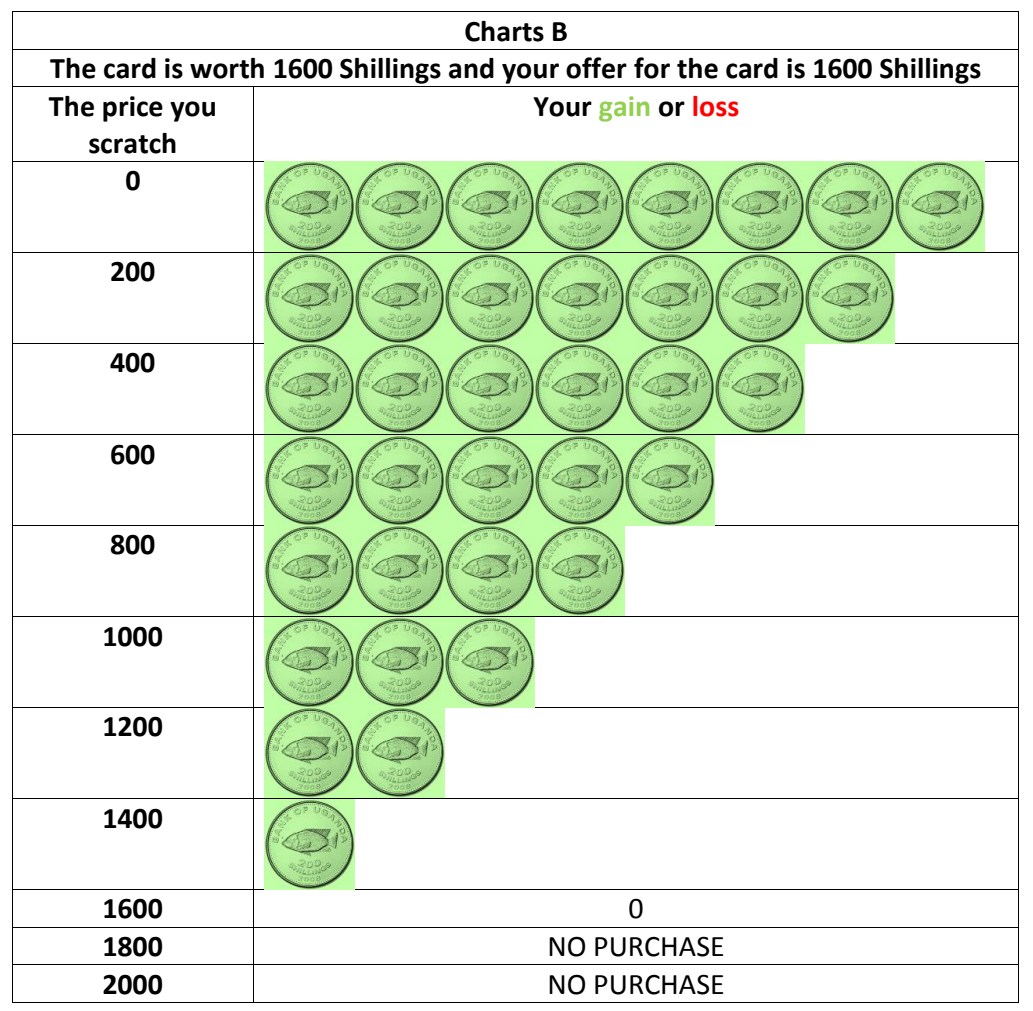

Figure D.3: Chart check B

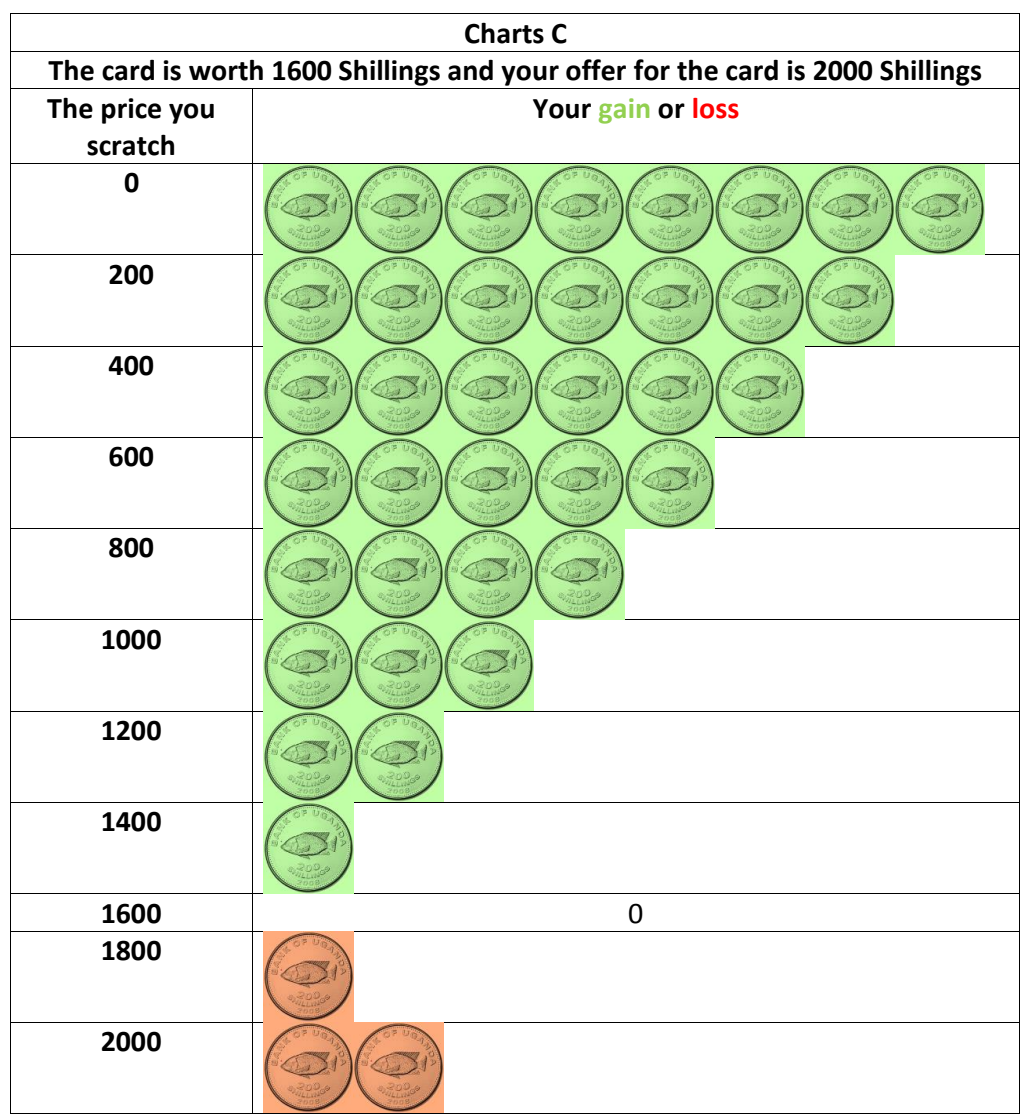

Figure D.4: Chart check C 